\title{
FORMAÇÃO DO PROFESSOR PESQUISADOR: A IMPORTÂNCIA DA FUNDAMENTAÇÃO EPISTEMOLÓGICA DAS DISSERTAÇÕES
}

\author{
Deise Becker KIRSCH ${ }^{1}$ \\ Renato Kraide SOFFNER ${ }^{2}$
}

RESUMO: O artigo analisa a formação do professor pesquisador e os enfoques teóricometodológicos das dissertações do Programa de Pós-Graduação em Educação Sociocomunitária, do Centro Universitário Salesiano de São Paulo. O objetivo do estudo é verificar os paradigmas das pesquisas produzidas por professores da Educação Básica inseridos no Mestrado, no período de 2005 a 2012. A metodologia baseia-se nos estudos de Gamboa (1996, 2009) com o Esquema Paradigmático para analisar as dissertações. O aporte teórico discute a formação do professor como pesquisador, bem como as concepções filosóficas: Positivismo, Fenomenologia, Marxismo e Teoria da Complexidade que permeiam as dissertações produzidas no Programa. Essa discussão é relevante na medida em que contribui para a delimitação dos fundamentos epistemológicos nas pesquisas em Educação Sociocomunitária e identifica elementos centrais para a formação do professor da Educação Básica na investigação científica.

PALAVRAS-CHAVE: Paradigmas de pesquisa. Educação sociocomunitária. Professor pesquisador.

\section{Palavras iniciais}

A ideia desse estudo nasce de uma inquietação que envolve dois elementos centrais: a consolidação da formação do professor pesquisador a partir do ingresso na Pós-Graduação Stricto-Sensu e a fundamentação epistemológica das pesquisas em Educação Sociocomunitária, do Programa de Pós-Graduação em Educação (PPGE), do Centro Universitário Salesiano de São Paulo (UNISAL).

Dessa maneira, nossa discussão parte das seguintes questões: quais são os enfoques teórico-metodológicos das dissertações de Mestrado em Educação do UNISAL? A partir dos paradigmas das dissertações, qual a consistência epistemológica da formação do professor pesquisador?

\footnotetext{
${ }^{1}$ Doutora em Educação. UFSCar - Universidade Federal de São. Pós-graduação em Educação. São Carlos - SP - Brasil. 13565-905. IFPR. Instituto Federal do Paraná. Curitiba - SP - Brasil. 82530-230 deisekirsch@yahoo.com.br

${ }^{2}$ Doutor em Tecnologia Educacional. UNICAMP - Universidade Estadual de Campinas. Campinas - SP - Brasil. 13083-970. Pós-Doutor em Tecnologia Educacional. MIT - Massachusetts Institute of Technology. Cambridge - Estados Unidos. 02139. UNISAL - Centro Universitário Salesiano de São Paulo. São Paulo - SP - Brasil. 05060-00. É Professor Pleno II da FATEC (Centro Paula Souza) rksoffner@uol.com.br
} 
Esse estudo se justifica na medida em que investiga a inserção no PPGE/UNISAL e se esta está fazendo a diferença na formação e desenvolvimento docente dos sujeitos, considerando que mais de $70 \%$ dos alunos do PPGE são professores da Educação Básica. Investiga sob dois elementos: a concepção da Educação Sociocomunitária, considerando a filosofia Institucional: educar para a autonomia, para a emancipação e para a transformação social; e no que se refere à produção científica do professor pesquisador no que diz respeito à fundamentação epistemológica das suas dissertações.

\section{Estrutura da investigação}

Diante das questões de pesquisa, utilizamos como referencial metodológico, num primeiro momento, o levantamento exploratório da literatura sobre os enfoques filosóficos contemporâneos (TRIVIÑOS, 2013) que dão suporte às pesquisas em educação de um modo geral, assim como a identificação e discussão em torno dos paradigmas utilizados no PPGE/UNISAL ao longo de sua existência.

A partir desse levantamento foi possível nomear e discutir acerca do Positivismo, da Fenomenologia, do Marxismo e da Teoria da Complexidade como fundamentos epistemológicos e filosóficos de pesquisas em Educação. Paralelo a esses fundamentos há o estudo bibliográfico sobre a formação do professor como pesquisador a partir da sua inserção em Programa Stricto Sensu.

Num segundo momento do trabalho, ocorre a coleta de dados das dissertações de Mestrado produzidas no PPGE/UNISAL, no período de 2005 a 2012, e, baseado no Esquema Paradigmático proposto por Gamboa (1996, 2009), há a construção de um instrumento, a fim de identificar dados essenciais das dissertações, tais como: enfoque teórico-metodológico; técnicas e instrumentos de coleta de dados; maneira de analisar, abstrair, generalizar e classificar o objeto científico; e, ainda, concepções de homem e educação.

De acordo com Gamboa (1996), a construção do Esquema Paradigmático pode ser organizada a partir de níveis e/ou pressupostos, o que "[...] subentende uma prévia tipificação das abordagens metodológicas, assim como de outras categorias relativas às diversas técnicas de pesquisa [...]" (GAMBOA, 1996, p.56).

A partir do Esquema Paradigmático é possível fazer um mapeamento dos enfoques teórico-metodológicos bem como os pensamentos que existem em torno da 
produção de conhecimentos (GAMBOA, 1996, 2009) e, assim, estruturar a produção científica em questão.

No terceiro e último momento, é possível estabelecer, a partir da análise paradigmática das dissertações, relações entre essa produção científica e a formação dos professores pesquisadores no Programa Stricto Sensu.

\section{Pressupostos teóricos}

São poucas as pesquisas que investigam pesquisas (GAMBOA, 1996) pelo fato de se considerar os estudos próprios de quem os faz; entretanto, é possível perceber que há em muitas pesquisas dos Programas de Pós-Graduação Stricto Sensu uma riqueza de dados a serem analisados, no intuito de identificar elementos importantes e que são comuns em muitos estudos, além das possibilidades de desvelar as características de cada Programa.

No Curso de Mestrado em Educação do UNISAL a maioria dos seus alunos são professores da Educação Básica, o que significa que o Programa está participando da constituição de docentes pesquisadores. Considerando o histórico de formação de professores, essa estatística é relevante, isso porque, conforme aponta Fazenda (1999, p.80)

[...] o educador, na maioria dos casos, era apenas objeto das pesquisas. A falta de formação em pesquisa e a ausência de uma linguagem pedagógica própria conduziram-no ao isolamento da sala de aula, isolamento esse agravado pelo desprestígio da carreira e falta de tempo para reflexão e estudo.

Além de esse dado ser essencial para o campo da formação de educadores, esse estudo tem importância também pela nossa preocupação em torno da qualidade dessa constituição do professor como pesquisador durante a realização do Curso de Mestrado. Iniciar no caminho da investigação científica é, muitas vezes, um grande desafio para o docente, como também é para o Programa de Pós Graduação Stricto Sensu que acolhe o sujeito e tem responsabilidade com sua formação Isso porque é necessário e importante que todo profissional em educação tenha o mínimo de clareza em relação à base teórica e metodológica do trabalho científico.

Nesse sentido, fazer pesquisa requer trabalho mental árduo, discussão teórica e epistemológica, e é isso que diferencia e identifica o pesquisador dos demais sujeitos. Para Japiassú (1995, p.86) “O intelectual define-se e afirma-se pelo caráter diferenciado 
do seu trabalho. Enfim, ele afirma-se como alguém que tem direito ao pensamento e à paixão por esse pensamento (esta paixão se denomina "filosofia")."

Sendo assim, o nascimento do ato de pesquisar tem suas bases na filosofia, no momento em que busca resposta acerca do mundo e do homem. Os questionamentos e as bases da investigação, consequentemente, terão seu desenvolvimento a partir de um determinado paradigma, mesmo que muitas vezes implícito e sem a consciência do pesquisador em demonstrá-lo no texto. À Ciência cabe estruturar os procedimentos necessários a essa investigação científica (CHIZZOTTI, 1998).

Esse é um dos motivos que faz com que discutamos acerca das tendências filosóficas mais estudadas e citadas na literatura científica, bem como no PPGE/UNISAL, buscando que estas contemplem os diferentes olhares que envolvem as produções em pesquisa educacional, especialmente em Educação Sociocomunitária.

Elencamos, dentre as correntes de pensamento contemporâneo: o Positivismo, a Fenomenologia, o Marxismo, e a Teoria da Complexidade. Torna-se relevante, de forma breve, destacar algumas características dessas tendências filosóficas.

O Positivismo é uma das concepções filosóficas e predominou no século XIX, tendo como fundador Augusto Comte. De acordo com os paradigmas de pesquisa (CHIZZOTTI, 1998) de estudo dos fatos sociais, o positivismo foi o primeiro a surgir.

Para Comte (1876, p.67) existem três estados do conhecimento:

[...] cada braço de nossos conhecimentos, passa por três estados teóricos diferentes, sucessivamente: o estado teológico, ou fictício; o metafísico, ou abstrato; o estado científico, ou positivo. Daí, três espécies de filosofias, ou sistemas gerais de concepções sobre o conjunto de fenômenos que se excluem mutuamente: o primeiro, é o ponto de partida necessário da inteligência humana; o terceiro, seu estado físico definitivo; o segundo, é unicamente destinado a servir de transição.

O autor, desse modo, afirma que o verdadeiro conhecimento advém dessa corrente positivista, não descartando os demais estados, porém os colocando apenas como provisórios, transitórios e/ou de passagem, ou seja, necessários para a chegada ao terceiro estado.

Segundo Comte (1876, p.73), a filosofia teológica e a metafísica foram importantes como ponto de partida, pois, é a partir delas que se tem a filosofia positivista e “[...] o verdadeiro estado definitivo da inteligência humana [...]". 
Observamos nesse positivismo de Comte (1876) a severidade e rigidez de princípios acerca do conhecimento.

Nesse paradigma, tem importância a observação fiel dos fatos (externos ao sujeito) e que, a partir desses dados particulares, é possível conceder significado geral e universal. Comte (1876) em seu trabalho revela essa concepção quando expõe que todos os fenômenos estão sujeitos a leis naturais invariáveis.

A palavra positivo, desse modo, está diretamente relacionada ao sentido do real, do útil, da certeza, do preciso e do organizar (RIBEIRO JUNIOR, 1991; TRIVIÑOS, 2013). Isso se refere à necessidade de estudo e de conclusões concretas, palpáveis, para não dizer apenas mensuráveis, do conhecimento sistematizado de modo a não deixar dúvidas nem espaço para ociosidades.

A Fenomenologia nasce no final do século XIX e início do século XX com Husserl, embora outros autores tenham usado essa palavra antes de Husserl (MOREIRA, 2004). Como estudo das essências (TRIVIÑOS, 2013; MOREIRA, 2004; DARTIGUES, 2002), a Fenomenologia considera que o mundo está posto e, a partir disso, é possível descrever e esclarecer as experiências vivenciadas (TRIVIÑOS, 2013).

As essências, desse modo, "[...] referem-se ao sentido ideal ou verdadeiro de alguma coisa, dando um entendimento comum ao fenômeno sob investigação." (MOREIRA, 2004, p.84). Isso significa afirmar que a Fenomenologia preocupa-se com o sentido e o significado desse fenômeno. Além disso, esse paradigma de pesquisa busca entender a realidade em todos os aspectos da vivência humana.

Para Bueno (2003, p.19), na Fenomenologia

[...] o seu papel é o de distinguir e revelar o que há de essencial na percepção do fenômeno, o que requer a suspensão dos juízos sobre a realidade que nos cerca. É como se o indivíduo adotasse uma espécie de abandono provisório do mundo para melhor captá-lo. Husserl denominou esse processo de redução fenomenológica ou epoché.

Essa suspensão de juízo é marcante na obra de Merleau-Ponty (1994) que, seguidor da Fenomenologia de Husserl, coloca como fundamental esse abandonar-se, provisoriamente, de certos valores, de preconceitos, para que se compreenda o objeto em investigação.

Outro ponto relevante da Fenomenologia, conforme Triviños (2013), é a intencionalidade da consciência humana ao olhar para o objeto. Essa intenção está relacionada ao sujeito buscar o entendimento acerca de um fenômeno. E, esse fenômeno, significa “[...] a percepção desse objeto que se torna visível à nossa 
consciência.” (MOREIRA, 2004, p.65), ou seja, é o dado que apreendo em minha consciência.

Considerando o exposto, a intencionalidade está associada à vivência, ao que de fato ocorreu. Segundo Moreira (2004, p.84 e p.85)

[...] a ideia da intencionalidade é uma forma de lidar com o problema imanente-transcendente. O imanente é o que é dado adequadamente (por exemplo, nós vemos a parte frontal de uma árvore) e o transcendente é o que objetivamos ou pretendemos (por exemplo, a árvore).

Isso revela que, num primeiro momento, precisamos entender o que estamos percebendo, o objeto que captamos, mas, posteriormente, faz-se necessário a compreensão do todo, da essência, que, muitas vezes, ultrapassa o que adquirimos pelos órgãos do sentido.

Desse modo, temos a clareza que a consciência é ativa, pois dotada de intencionalidade, atribui sentido aos objetos. Para Merleau-Ponty (1994, p.16):

Graças a essa noção ampliada da intencionalidade, a compreensão fenomenológica distingue-se da intelecção clássica, que se limita às naturezas verdadeiras e imutáveis, e a fenomenologia pode tornar-se uma fenomenologia da gênese. Quer se trate de uma coisa percebida, de um acontecimento histórico ou de uma doutrina, compreender é reapoderar-se da intenção total [...]

Sendo assim, as investigações na concepção da Fenomenologia, especificamente dos fenômenos sociais, dão a possibilidade de ultrapassar o que se tem nas pesquisas nas ciências naturais ou exatas, muito ligadas a variáveis controláveis, determinismos e leis universais. No estudo do contexto social a partir da Fenomenologia trabalha-se com a intencionalidade, a consciência, a percepção, e não com o mundo que eu penso, mas com o que vivo no mundo e com o mundo abundante (MERLEAU-PONTY, 1994).

O Marxismo advém dos estudos de Marx que é caracterizado como "[...] um pensador jovem-hegeliano diretamente influenciado por Feuerbach.” (FREDERICO, 1995, p.11). A ideologia e a ciência do marxismo denominam-se Materialismo e é o oposto do Positivismo.

Diversos autores escrevem e aprofundam essa abordagem Marxista, mas para Minayo (2012, p.24) o marxismo “[...] considera a historicidade dos processos sociais e dos conceitos, as condições socioeconômicas de produção dos fenômenos e as contradições sociais [...]." 
Sem dúvida, o marxismo merece destaque como um dos enfoques teóricos nas práticas de pesquisas educacionais, pois considera o contexto sociocultural e o processo contraditório existente nos fenômenos analisados. Nesse estudo, apesar de reconhecermos a existência do caráter político e idealista dessa abordagem, esse não é o nosso foco, e sim, como dito anteriormente, a base epistemológica da teoria e que repercute nas investigações científicas.

Richardson (1999, p.44) quando escreve sobre essa abordagem, coloca que para Marx e Engels “[...] mundo existe independentemente da consciência [...]" e que no nosso mundo os objetos se diferenciam em sua forma, tamanho, espessura, volume, etc., e, desse modo, todos existem. Ainda, para o Materialismo, “[...] a matéria é uma categoria que indica a realidade objetiva dada ao homem por meio de suas sensações e que existem independente dele.” (RICHARDSON, 1999, p.44).

Esse conceito de matéria como primordial, deixando o espírito num segundo aspecto, de acordo com Triviños (2013), refere-se ao materialismo filosófico. O materialismo dialético, fundamento do marxismo "[...] tem como base seus princípios a matéria, a dialética e a prática social, mas também aspira ser a teoria orientadora da revolução do proletariado.” (TRIVIÑOS, 2013, p.51).

A dialética, por sua vez, preocupa-se na investigação das contradições existentes na realidade, “[...] está vinculada ao processo dialógico de debate entre posições contrárias [...]", conforme aponta Richardson (1999, p.45). Em torno da dialética, Minayo (2012, p.24) revela que esta “[...] trabalha com a valorização das quantidades e qualidades, com as contradições intrínsecas às ações e realizações humanas [...]”. Nesse conflito de ideias que geram verdades para um determinado tempo, evidenciamos a concepção da transitoriedade dos fenômenos, visto que esse processo, em espiral, envolve sempre uma tese, antítese, síntese, e assim sucessivamente.

Desse modo, o materialismo dialético presente no marxismo, “[...] é a única corrente de interpretação dos fenômenos sociais que apresenta princípios, leis e categorias de análise.” (RICHARDSON, 1999, p.46).

Considerando o paradigma marxista para o desenvolvimento de um estudo científico, especialmente na área da educação, faz-se importante que o pesquisador tenha bem claro os conceitos acerca da teoria além de uma trajetória formativa nessa linha de investigação. O pesquisador precisa conhecer a concepção dialética e os conceitos capitais do materialismo histórico (TRIVIÑOS, 2013). 
A Teoria da Complexidade deixa de lado os princípios que norteiam o paradigma clássico, ou a chamada teoria cartesiana, para olhar o mundo, os fenômenos e o fazer ciência considerando todos os fatores que estejam interligados aos acontecimentos bem como àqueles que parecem, num primeiro momento, não estar diretamente relacionados aos fatos.

Para Morin (2003) o paradigma da complexidade é muito mais que uma epistemologia ou metodologia, pois ele revela que o que rege os fenômenos do pensamento é o próprio pensar sobre a realidade e a natureza dessa realidade. Assim, nessa teoria, é possível se trabalhar com elementos que, num primeiro momento, podem parecer contraditórios, mas no fundo possuem a mesma raiz.

Para entendermos essa concepção, podemos partir da definição de complexidade posta por Morin (1990, p.17):

[...] é um tecido (complexus: o que é tecido em conjunto) de constituintes heterogéneos inseparavelmente associados: coloca o paradoxo do uno e do múltiplo [...] é efectivamente o tecido de acontecimentos, acções, interacções, retroacções, determinações, acasos, que constituem o nosso mundo fenomenal.

Tal citação demonstra que a complexidade é o oposto a qualquer pensamento ou paradigma de simplificação, de pormenorizar fatos para entendê-los. Surge, assim, a noção de sistema, de "todo", mas "que não se reduz à "soma" das suas partes constitutivas." (MORIN, 1990, p.25).

Isso porque quando vemos o "todo", vemos uma composição, e nesse "todo" está um emaranhado de relações, e não simplesmente elementos justapostos lado a lado. Se apenas somarmos os elementos não teremos o resultado do todo, pois as relações e as interseções não terão sido fecundadas para atingir esse "todo".

Essa definição se aproxima da ideia de recursividade, de totalidade ativa, a qual significa que tem a capacidade de reproduzir-se com certa frequência, de reorganizar-se de modo permanente (ESTRADA, 2009).

O conhecimento, desse modo, é inacabado, incerto, e as explicações sobre os fenômenos precisam ocorrer dialeticamente. Ciência, assim entende-se, não pode ser delimitada ou limitar-se, e sim estar constantemente aberta para a imprevisibilidade.

Trabalhar com e diante da incerteza é uma das premissas e, como Soffner (2012) expõe, precisamos perguntar o papel da ciência no tempo e no espaço de hoje e como nossa secular vivência científica pode nos auxiliar frente ao incerto. Ainda, 
perguntamos em que medida os processos educativos, considerando a práxis educativa, pode corroborar no fazer Ciência e na própria produção científica.

A partir dessas breves ideias acerca dos fundamentos filosóficos que podem embasar a pesquisa científica, é importante sinalizar que, independentemente de qual abordagem seja utilizada pelo pesquisador, investigar significa ter clareza da seriedade e do comprometimento que envolve esse trabalho.

Conforme escreve Demo (2010, p.16):

Pesquisa é princípio científico, mas igualmente princípio educativo. Autoria não é marca apenas do pesquisador supremo, mas de todos os docentes que produzem textos próprios, reconstroem conhecimentos com alguma originalidade, aprendem a escudar-se na autoridade do argumento, não no argumento da autoridade.

São essas ideias que embasam o início e o desenvolvimento da pesquisa e o investigador aprende essa nobre atividade, mergulha no mundo da incerteza, do problema a ser pesquisado, do estudo aprofundado, da construção de fundamentação teórica e metodológica e da arte de escrever, de questionar e de discutir no campo da educação.

Pesquisar não se reduz a assistir aula nem a decorar conteúdos para serem reproduzidos na avaliação. Pesquisar possibilita sujeito ativo e interativo com os colegas e, principalmente com o próprio conhecimento.

Além disso, o professor pesquisador, se ainda não observa sua realidade escolar com inquietação e olhar apurado, vai fazê-lo assim que ingressar no campo da investigação científica e, mais que isso:

Quando o aluno aprende a lidar com método, a planejar e a executar pesquisa, a argumentar e a contra-argumentar, a fundamentar com autoridade do argumento, não está só "fazendo ciência", está igualmente construindo a cidadania que sabe pensar. (DEMO, 2010, p.20).

O autor apresenta a ideia da educação cidadã através da pesquisa, desse saber pensar e que, segundo o próprio Demo (2010, p.21), significa “[...] saber construir e usar ciência e tecnologia para fins sociais éticos e cidadãos." Ou seja, quem ainda pensa que pesquisar é ato para superdotados, que são cientistas vestindo jaleco branco isolados em seus laboratórios, está um tanto enganado. Muitos profissionais estão envolvidos no campo da investigação científica e esse número tende a crescer se continuar o investimento desde os cursos de graduação, contribuindo, assim, para a formação de sujeitos e de uma sociedade melhor. 
Dessa maneira, a atividade de pesquisa trabalha com o desenvolvimento de pessoas críticas e preocupadas com aspectos teóricos e práticos acerca do conhecimento. Por isso vale ressaltar novamente que aqui não estamos escrevendo sobre qualquer pesquisa, estamos examinando a investigação científica com todas suas prerrogativas. Isso requer uma análise cuidadosa sobre a temática e Demo (2006) a faz aproximando os conceitos de educação, pesquisa e emancipação, o que vai ao encontro do nosso PPGE, em especial quando aborda o conceito de emancipação:

[Emancipação] É processo histórico de conquista e exercício da qualidade de ator consciente e produtivo [...] é fenômeno teórico e prático ao mesmo tempo. Tem momento relevante na tomada de consciência crítica, quando o ser social descobre sua condição histórica, que em parte ela é dada, em parte é causada. (DEMO, 2006, p.78).

Esse exercício de que escreve o autor refere-se diretamente ao ato de pesquisar, sendo momento único e dinâmico na formação e desenvolvimento de todo e qualquer tipo de profissional, em especial àqueles que trabalham com a docência, que "professam"” o conhecimento, mas não apenas no sentido de ensino, mas de construção conjunta e crítica de saberes e de transformações de realidades em que se vive.

Por estudarmos e pesquisarmos no campo educativo, este requer o envolvimento em diferentes e singulares realidades, o que exige cuidado investigativo. Se comparada às ciências naturais, por exemplo, a área da educação é bastante complexa, pois apresenta

[...] caráter de campo de confluência de várias disciplinas próprio da área. Essa complexidade de natureza e de composição provoca no campo da educação uma variedade de problemas, que vêm desafiando seus pesquisadores e os formadores de futuros investigadores. (LÜDKE, 1998, p.25).

Esses motivos fazem com que os estudos não envolvam objeto científico estático, que pode ser investigado em laboratório, extremamente controlado e utilizando variáveis constantemente manipuláveis. O laboratório de pesquisa em educação é o mundo social e escolar, são as realidades que sofrem muitas influências externas e propriamente internas aos sujeitos que estão envolvidos no contexto, ou seja, difícil e, às vezes, impossível de controlar.

\section{Para não finalizar ...}

${ }^{3}$ Grifo nosso. 
O que podemos concluir até o presente momento do estudo é que quando olhamos para o PPGE/UNISAL, observamos o quantitativo significativo de professores da Educação Básica em busca da capacitação para a pesquisa científica através do curso de Mestrado. Esse aspecto é positivo na medida em que eles são profissionais inseridos no mercado de trabalho, buscam novos horizontes para sua formação e desenvolvimento docente, além de estarem contribuindo, direta ou indiretamente, para suas práticas pedagógicas.

Além disso, nossa investigação, ao buscar mapear os paradigmas das pesquisas em Educação Sociocomunitária, identificar a formação do professor pesquisador, bem como a estrutura do Programa Stricto Sensu, está preocupada com a consistência da fundamentação epistemológica da investigação científica e, consequentemente, com a qualidade da formação dos investigadores.

Apesar de ainda não termos o mapeamento final com o quantitativo de dissertações e seus respectivos enfoques teórico-metodológicos, podemos afirmar que os profissionais que ingressaram no PPGE/UNISAL não concluíram o curso com o mesmo pensamento de quando iniciaram. Eles têm outro olhar acerca da sua realidade escolar, além de terem desenvolvido a capacidade fundamental ao pesquisador: produzir cientificamente.

Nesse sentido, o professor pesquisador, como foi dito, passou a observar sua realidade escolar com inquietação e olhar apurado, a partir do ingresso no campo da pesquisa científica, enquanto o aluno "fazendo ciência" está construindo cidadania.

Sendo assim, através da pesquisa é possível uma educação cidadã, do saber pensar que, segundo o próprio Demo (2010, p.21) significa “[...] saber construir e usar ciência e tecnologia para fins sociais éticos e cidadãos.” Ou melhor, quem ainda pensa que pesquisar é ato para superdotados, que são cientistas de branco isolados em seus laboratórios, está um tanto enganado. Muitos profissionais, na escola ou na universidade, estão envolvidos no campo da investigação científica e esse número tende a crescer com os incentivos na área nas últimas décadas, contribuindo, assim, para a formação de sujeitos e de uma sociedade melhor.

Portanto, parece inevitável a contribuição da pesquisa científica na formação do professor, sempre prezando pela utilização do rigor do método científico na produção a fim de manter padrão e qualidade no fazer ciência. Nesse percurso, os Programas Stricto Sensu tem papel fundamental, na medida em que possibilitam uma 
formação científica para os profissionais da educação, em especial para aqueles que estão do dia a dia da Educação Básica.

\section{RESEARCHER TEACHER FORMATION: THE IMPORTANCE OF EPISTEMOLOGICAL FOUNDATION OF THESES}

ABSTRACT: The article analyzes the researcher teacher formation and the theoretical and methodological dissertation approaches of the Post-Graduation in SocioCommunity Education Program of Salesiano's University Center of São Paulo. The study aims to verify the paradigms of researches produced by the teachers included in the Master's Degree, from 2005 to 2012. The methodology is based on Gamboa's studies $(1996,2000)$ of the paradigmatic scheme for dissertations analysis. The theoretical framework discusses the teacher formation as a researcher, as well as the Positivism, Phenomenology, Marxism and Complexity Theory philosophical conceptions that permeate the dissertations produced in the Program. This discussion is relevant insofar as it contributes to defining the epistemological foundations in research on Socio-community Education and identifies key elements for training of Basic Education teachers in scientific research.

KEYWORDS: Research paradigms. Socio-community Education. Researcher teacher.

\section{REFERÊNCIAS}

BUENO, E. R. de A. Fenomenologia: a volta às coisas mesmas. In: PEIXOTO, A. J. (Org.). Interações entre fenomenologia \& Educação. Campinas: Alínea, 2003. p.9-42.

CHIZZOTTI, A. Pesquisa em ciências humanas e sociais. 3.ed. São Paulo: Cortez, 1998.

COMTE, A. Princípio de filosofia positiva. São Paulo: Editorial Paulista, 1876.

DARTIGUES, A. O que é fenomenologia? 8.ed. São Paulo: Centauro, 2002.

DEMO, P. Educação científica. Boletim Técnico do Senac: Revista de Educação Profissional, Rio de Janeiro, v.36, n.1, p.15-25, jan./abr. 2010.

Pesquisa: princípio científico e educativo. 12.ed. São Paulo: Cortez, 2006.

ESTRADA, A. A. Os fundamentos da teoria da complexidade em Edgar Morin. Revista Akrópolis, Umuarama, v.17, n.2, p.85-90, abr./jun. 2009.

FAZENDA, I. A pesquisa como instrumentalização da prática pedagógica. In: FAZENDA, I. (Org.). Novos enfoques da pesquisa educacional. 3.ed. São Paulo: Cortez, 1999. p.75-84. 
FREDERICO, C. O jovem Marx: (1843-44: as origens da ontologia do ser social). São Paulo: Cortez, 1995.

GAMBOA, S. S. (Org.). Pesquisa educacional: quantidade-qualidade. 7.ed. São Paulo: Cortez, 2009.

Epistemologia da pesquisa em educação. Campinas: Praxis, 1996.

JAPIASSÚ, H. A crise das ciências humanas. In: FAZENDA, I. (Org.). A pesquisa em educação e as transformações do conhecimento. 6.ed. Campinas: Papirus, 1995. p.7586.

LÜDKE, M. Pesquisa em educação: conceitos, políticas e práticas. In: GERALDI, C. M. G.; FIORENTINI, D.; PEREIRA, E. M. de A. (Org.). Cartografias do trabalho docente: professor (a) - pesquisador (a). Campinas: Mercado das Letras, 1998. p.23-32.

MERLEAU-PONTY, M. Fenomenologia da percepção. São Paulo: Martins Fontes, 1994.

MINAYO, M. C. de S. (Org.). Pesquisa social: teoria, método e criatividade. 31.ed. Petrópolis: Vozes, 2012.

MOREIRA, D. A. O método fenomenológico na pesquisa. São Paulo: Pioneira Thomson Leraning, 2004.

MORIN, E. Os sete saberes necessários à educação do futuro.8.ed. São Paulo: Cortez, 2003.

Introdução ao pensamento complexo. Lisboa: Instituto Piaget, 1990.

RIBEIRO JUNIOR, J. O que é positivismo. 10.ed. São Paulo: Brasiliense, 1991.

RICHARDSON, R. J. Pesquisa social: métodos e técnicas. São Paulo: Atlas, 1999.

SOFFNER, R. K. Concepções tecnológicas e educação: modelagem, complexidade, auto-organização e descentralização. Série-Estudos: Periódico do Programa de PósGraduação em Educação da UCDB, Campo Grande, n.33, p.91-100, jan./jun. 2012.

TRIVIÑOS, A. N. S. Introdução à pesquisa em ciências sociais: a pesquisa qualitativa em educação. São Paulo: Atlas, 2013. 